\title{
Nanotechnologies: a review of inventions and utility models. Part II
}

\author{
L.A. Ivanov ${ }^{1 *}$ (D) I.A. Kapustin² (iD, O.N. Borisova3 ${ }^{3}$ (D) Zh.V. Pisarenko ${ }^{4}$ (iD) \\ ${ }^{1}$ Russian Academy of Engineering, Moscow, Russia; \\ ${ }^{2}$ A.N. Kosygin Russian State University, Moscow, Russia; \\ ${ }^{3}$ Russian State University of Tourism and Service; Cherkizovo, Moscow region, Russia; \\ ${ }^{4}$ Saint-Petersburg State University, Saint-Petersburg, Russia \\ *Corresponding author: e-mail: L.a.ivanov@mail.ru
}

(c) Authors, 2020

\begin{abstract}
A brief review of patents is given. The research performed by scientists, engineers and specialists in the area of nanotechnologies and nanomaterials resulted in increased efficiency of construction, housing sector and adjacent fields of economy.For example, an invention «A method to produce metal-polymer nanocomposite materials with metal nanoparticles» refers to the method used in production of polymer articles with nanoparticles of silver or copper, widely applied in different engineering areas and used as antibacterial material. The invention provides environmental responsible and reagentless method to obtain polymer articles with metal nanoparticles which size is $5-15 \mathrm{~nm}$ and boosts rangeof polymers, including hemicrystalline and amorphous glass-like ones.

The invention «Exfoliated polyurethane nanocomposite with polyfluoroalkyl groups» refers to design of composite and nanocomposite materials and can be used to create materials applied in polymer industry, in particularly, in production of solidcoatings for sport facilities, hydroinsulation and roof coatings, construction sealers and tribotechnical articles.

The specialists can also be interested in the following inventions in the area of nanotechnologies: a method to obtain metal nanopowder from lead bronze wastes in distilled water, a method to produce collector plates, a water defluoridation method,an exfoliated polyurethane nanocomposite with polyfluoroalkyl groups, amultifunctional grease lubricant for heavy loaded friction joint, a thermostatic system to perform nanocalorimetric measurements, a self-hardening composition based on polydimethylsiloxane et al.
\end{abstract}

KEYWORDS: nanotechnologies in construction, nanopowder materials, nanocomposite materials, nanoparticles, calorimetric measurement.

FOR CITATION: Ivanov LA., Kapustin I.A., Borisova O.N., Pisarenko Zh.V. Nanotechnologies: a review of inventions and utility models. Part II. Nanotechnologies in Construction. 2020, Vol. 12, no. 2, pp. 71-76. DOI: 10.15828/2075-8545-2020-12-2-71-76.

\section{INTRODUCTION}

$\mathrm{T}$ The practical application of the results achieved by scientists, engineers and specialists can become efficient tool to increase number of import-substituting goods and to rise labor productivity. An invention is known to be a new, with distinctive characteristics technical solution with proved efficiency (new technologies, structures or new substances). The paper reviews the essence, technical result and practical value of some inventions concerning nanotechnologies.

\section{MAIN PART}

A method to produce metal-polymer nanocomposite materials with metal nanoparticles (RU 2711427 C1)

Theinventionrefersto the method used to obtain polymer products with silver or copper nanoparticles widely applied in different engineering areas and used as antibacterial material [1]. The method consists ofpullingprolateshapepolymer product in organic solvent that contains dissolved silver or copper salt, according to crazing 
mechanism or when impregnating open-porous polymer matrix of physically active liquid-saturated medium with dissolved silver or copper salt. Hemicrystalline glass-like polymers which crystallinity is $20-80 \%$ or amorphous glass-like polymers are used as initial polymer. Silver or copper salt is selected among bromide, chloride, nitrate or their mixture.

After that $150 \%$ or $200 \%$ pulled product is dried and it is exposed toionizing radiation in the presence of hydroalcoholic medium with alcohol that provides deactivation of forming $\mathrm{OH}$-radicals. Radiation is performed with efficient quantum energy that provides reduction of the metal ions and formation of nanoparticles directly in nanoporous structure of polymer matrix, for example, under $16-25 \mathrm{keV}$. The invention provides environmental responsible and reagentless method to obtain polymer articles with metal nanoparticles which size is $5-15 \mathrm{~nm}$ and boosts polymer range, including hemicrystalline and amorphous glass-like ones.

\section{A method to obtain metal nanopowder from lead bronze wastes in distilled water(RU $2710707 \mathrm{C1}$ )}

The waste products of lead copper are exposed to spark-erosion dispergating in distilled water with pulse frequency95...105 Hz, electrode resistance $190 \ldots 200 \mathrm{~V}$ and condenser capacity $65,5 \mathrm{uF}$, after that separation of nanosize particles from large-size ones is performed by centrifuging solution [2]. Average cost per unit of energy for the production of the spark-erosion powder made of lead copper wastes is $2,4 \mathrm{~kg} / \mathrm{kWh}$, that is less than in other methods used for the same aim. The technical result is obtaining nanopowder from lead copper wastes with regular spherical particles and low energy consumption, ecological safety of spark-erosion dispergation (SED).

Nanopowder materials obtained by lead copper waste spark-erosion dispergating can be efficiently used to apply wear-resistant, antifrictional, corrosion-resistant, antiscoring coatings - to restore and strengthen units of equipment in mining and metallurgical industry, vehicles, ships, energy supply and oil industries as well as to spray decorative coatings.

\section{A method to produce collector plates (RU 2710758 C1)}

The invention refers to electric engineering, in particularly, to production of collector plate used in directcurrent machines and can be applied in machine building plantsproducing direct-current machines. As collectors in direct-current machines perform under high rotary velocity and mechanical loads and are exposed to dynamic impacts, collector plates are to meet following requirement: high electric- and thermal conductivity, low and stable transition resistance, corrosion and friction resistance, durability, proper plasticity, higher softening temperature, specified processability [3].

Technical result is widened range of the methods for collector plates production and at the same time increased durability and electrical conductivity of the plates as well as decreased plate pressuring power. Furnace charge is prepared in paddle-type mixer, trapezoidal section plate is pressed on slanting hobs, after that melting is performed under $800^{\circ} \mathrm{C}$ temperature for 45 minutes and calibration is done under pressure $5 \mathrm{t} / \mathrm{cm}^{2}$. Furnace charge is prepared from 98,5 mass.\%copper electrolytic powder and 1,5 mass.\% carbon nanotubes modified with copper. Lubricant taken in quantity 2,0 mass. $\%$ of furnace charge weightis added into furnace charge. Lubricant is the result of mixing 50 mass.\% industrial oil and 50 mass.\% kerosene oil. That provides increased durability and electric conductivity of collector plates as well as decreased plate pressuring power.

A multifunctional grease lubricant for heavy loaded friction joints (RU 2711022 C1)

The invention refers to composition of multifunctional grease lubricant for heavy loaded friction joints that can be used in mobile machinery and stationary equipment mechanisms of different purposes [4]. Application of multifunctional grease lubricant in heavy loaded friction joints requires their composition to possess anti-wear/antiscoringadditives, and/or fine-disperse additives and fillers (molybdenum and wolfram disulfides, mineral carbon, fluoroplastic, colloidal carbon), and/or nanostructured functional additives of different nature.

Multifunctionalgreaselubricantcontains, mass.\%: gelling material $-4,0-25,0$; nanostructured functional additive - nanosize particles of borat and/or calcium carbonate $-0,5-5,0$; antioxidant $-0,2-0,5$; corrosion inhibitor - 0,0-2,0; additive with anti-wear and/or antiscoring properties $-0,0-3,0$; hard filler $-0,0-20,0$; base oil - up to 100 . Achieved result is decreased wear and scoring prevention due to formation of durable chemisorptive film, thatprotects surface from friction, in transition layer and modification gelling material fibers with borat and/or calcium carbonate nanosize particles in the course of formation of grease lubricants structural framework.

An exfoliated polyurethane nanocomposite with polyfluoroalkylgroups (RU 2711458 C2)

The invention refers to design of composite and nanocomposite materials and can be used to develop materials applied in polymer industry, in particularly, in manufacture of solid sport, hydroinsulation and roof coatings, construction sealers and tribotechnical articles [5]. Exfoliated polyurethane nanocomposite with polyfluoroalkyl 
groups is described. The composite contains oligobutadienediol, polymethylenepolyphenylenepolyisocyanate with isocyanate group content 29,3 mass.\%, glycerine, stannumdibutyldilaurate and modifier. At this modifier is montmorillonite preliminary dispersed with 1,1,3-trihydroperfluoropropanol-1 in ultrasound field with frequency $40 \mathrm{kHz}$ under $30^{\circ} \mathrm{C}$ in $\mathrm{n}$-heptane medium. The invention provides nanocomposite with increased thermal-oxidative resistance and water-repellency.

\section{A thermostaticsystemtoperformnanocalorimetricmeas urements (RU $2711563 \mathrm{C1}$ )}

The invention refers to instrument manufacture and can be used to conduct combined in-situ research of structure and thermophysical properties of different materials within wide temperature range [6]. The presented invention for thermostat control of new generation nanocalorimetric sensors makes it possible to place severalnanocalorimetric sensors of different types (XEN40014, XEN T08, FlashDSC chip) inside the frame. The system can be integrated into instrument group to measure thermophysical and structural parameters of the samples. The system boosts applicability of nanocalorimetric methods due to possibility to heat sample up to $450^{\circ} \mathrm{C}$ and to cool it up to $-20^{\circ} \mathrm{C}$. Moreover, the configuration of the system allows using sensors with two active zones, one of which can be reference cell.

The system consists of the frame made in such a way to link up connector and it possesses windows of radiotransparent material. The frame comprisesa nanocalorimetric sensor, a rectangular Peltier element, a heat-transport plate made of thermal-conductive material, a liquid-cooling system embedded into frame. The heat-transport plate has a hole to radiation transport, and the sensor with studied sample is fixed on this plate in such a way to provide displacement of sensor active part within hole projection. Electronic boards are embedded into the frame to provide possibility to connect different sensors. Technicalresultisimprovedqualityofconductedresearch.

\section{A subnanosecondelectron accelerator (RU 2711213 C1)}

Theinventionreferstosubnanosecond electron accelerator [7]. The accelerator contains nanosecond highvoltage impulse source, gas-filled generator of nanosecond voltage impulses and accelerating tube. The framework of the former is dismountable and it consists of two units between which fusible element is leaktight installed. An inner conductor of the second forming line is fixed on the fusible element with cone hollow isolator. The fusible element is connected to the second unit with the use of centering elements to provide mutual radialpulseof the conductors in the second forming line no more than $0.2 \mathrm{~mm}$. The first forming line is in the first unit, a trans- mitting line and accelerating tube are un the second unit. Impulse travel time in the transmitting line is $0.3-0.5 \mathrm{~ns}$ and the iterative impedance is $40-80 \mathrm{Ohm}$. The inner conductor of the transmitting line in the zone that joints tube isolator contains biconic radial projection that cuts opening distance between projection and core electrode in front of the projection.

The technical result is expanded performance characteristics of accelerator and keeping outcome parameters due to shorter length of the former, enhanced service and improved performance reliability in the presence of vibration and other destabilizing factors as well as due to improved mutual coincidence of conductors in the second forming line.

A method to produce fluorescent ceramics on the basis of complex oxides with garnet structure (RU 2711318 C2)

Theinventionrefersto the methods used to produce ceramic fluorescent and scintillation materials [8]. These materials are used as scintillator for X-ray computed tomography, screening equipment et al., as well as luminophor for solid-state lighting. The method allows obtaining nanostructures powders and fluorescent ceramics on the basis of them with the content of $\mathrm{Gd}, \mathrm{Ga}, \mathrm{Ce}, \mathrm{Al}$ and if it is necessary $\mathrm{Y}$.

The method consists of the following consistent stages: preparation of aqueous solution of salt of initial components with accurately specified concentrations; integration of these solutions taken in required quantity to provide proper composition; preparation of precipitant solution; pouring initial components solutions into precipitant solution; sediment detachment; drying; thermal treatment under $800-1000^{\circ} \mathrm{C}$; compacting and agglomerating under not less than $1500^{\circ} \mathrm{C}$. To keep stoichiometry the solutions of the initial components are split into two or more groups and their precipitation is conducted separately, and the amount of precipitator is chosen in such a way to provide total precipitation of the components of the group. Gadolinium and gallium are parts of different groups. The obtained residual mattersare mixed, jointly dried, and then are exposed to thermal treatment and other processing stages. The technical result is the possibility to obtain fluorescent ceramics on the basis of complex oxides with garnet structure of the accurately specified composition.

\section{A water defluoridationmethod (RU 2711741 C1)}

The invention refers to water treatment [9-11]. The technical result is removal of fluorine ions from natural and city water due to selective binding of fluoride-ions in water defluoridation method that is characterized by high adsorbability. The method is safe, simple and available as it employs bacterial cellulose modified with aluminium oxide $\left(\mathrm{Al}_{2} \mathrm{O}_{3}\right)$ nanolayer [12]. 
The invention is that water defluoridation methodincludes following stages: water is filtered through cylindrical filter structure which comprises a system that consists of $5 \mathrm{~cm}$ thin silica dioxide layer, $10 \mathrm{~cm}$ thin granulated absorbent carbon layer and $0.5 \mathrm{~cm}$ thin sorbent layer. Sorbent includes a material on the basis of bacterial cellulose modified with $\mathrm{Al}_{2} \mathrm{O}_{3}$ nanolayer. ItisdesirablethatthicknessofAl $\mathrm{O}_{3}$ nanolayerwouldbe $50 \mathrm{nmor} 100 \mathrm{~nm}$.

Novelty of the given method is to use a material on the basis of bacterial cellulose as a matrix. The bacterial cellulose possesses unique combination of necessary characteristics: high degree of crystallinity with great number of "anchored" hydroxyl groups on the surface, that favors formation of durable $\mathrm{Al}_{2} \mathrm{O}_{3}$ nanolayer.

\section{A self-hardening composition based on polydimethyl- siloxane (RU 2712558 C1)}

Rubbers, glues and sealers based on polydimethylsiloxane are applied in many industries and domestic spheres due to set of unique characteristics, such as high thermal resistance, frost resistance, high electric insulation properties, resistance to thermal, thermal-oxidative, ultra-violet impact, biological inertia. The main disadvantage of elastomer materials based on polydimethylsiloxane is low mechanical durability and it is caused by weak intermolecule interaction of polymer chains.

Technical result achieved due to implementation of the given invention boosts range of silicone elastomer compositions due to creation of new self-hardening transparent composition based on polydimethylsiloxane with high durability [13]. The given technical result is achieved due to creation of self-hardening composition consisting of polydimethylsiloxane with end 3-aminopropyl - dialcoxysylyl groups and nanogel.

\section{A method to enrich and recycle solid domestic waste (RU 2542116 C2)}

Technical task of the invention is to increase efficiency of enrichment and recycling solid domestic waste, to decrease recycling costs and to provide continuous process performance [14-16].

The posed task is solved in the following way: the solid wastes are sortedandbiodegradablecut fraction with size from -60 to $-100 \mathrm{~mm}$ is separated, it is exposed to gravity separation to obtain concentrate and tailings, at this gravity separation concentrate is consistently thermally treated (under $150^{\circ} \mathrm{C}$ for 1,5 hours till humidity content $38-40 \%$ ), grinded (in impact-cutting mill), screen separated by class $20 \mathrm{~mm}$ with obtaining undersize and oversize product, thenundersize product is dried (till humidity content $10-12 \%$ ) and it is crushed in roll mill. The crushed product is screen separated by class $5 \mathrm{~mm}$ and $10 \mathrm{~mm}$ with obtaining undersize and oversize product, then undersize product is separately crushed in roll mill and is screen separated by class $2 \mathrm{~mm}$ and $5 \mathrm{mmwith}$ obtaining undersize products and their consolidation in a final product (food fraction without any harmful mechanical admixtures); all oversize products are excluded from sorting process and are forwarded either to ground disposal or to thermal treatment (contain waste paper, leather, textile, rubber, plastic, wood).

\section{These are inventions in nanotechnological area that can be interesting for specialists:}

- A method to obtain modified carbon nanotubes [17].

- A method to obtain detonation nanodiamonds [18].

- A method to obtain nanocomposite material based on aluminum [19].

- A method to apply thin metal coatings [20].

- A fabric with antistatic characteristics [21].

- Nanoparticles-generatingdevice [22].

- A method to obtain strengthenednanocomposite with additional properties [23].

- A method to obtain functional coating on the basis of aluminium-carbon nanofibers [24].

- Composition of additive for break-in oil used ingear set testing [25].

- Synthesis of environmental responsible ferrum-huminnanofertilization [26].

- Production of ultradisperse nanocomposite [27].

\section{CONCLUSION}

It is known that it is precisely the popularization and introduction of inventions that is an important factor for the success of many successful companies. For example, General Electric, which entered world history as one of the most innovative companies of the $20^{\text {th }}$ century, is a company that was originally listed in the Dow Jones index in 1896 and is still there. Therefore, we hope that the information published in this section will be in demand and useful for specialists. Confirmation that articles from the "Invention Review" column are particularly popular is information on the number of views of materials, for example, in the full-text database of open access scientific journals Open Academic Journals Index OAJI (USA), link - http://oaji.net/ journal-detail.html? number $=6931$. 


\section{REFERENCES}

1. Arzhakova O.V., Dolgova A.A., Ruhlya E.G. et al. A method to produce metal-polymer nanocomposite materials with metal nanoparticles. Patent 2711427 RF C1.2020. Bul. № 2. (In Russian).

2. Ageev E.V., Ageeva E.V., Pereverzev A.S. A method to obtain metal nanopowder from lead bronze wastes in distilled water. Patent 2710707 RF C1.2020. Bul. № 1. (In Russian).

3. Dudkin D.G. Amethodtoproducecollectorplates.Patent 2710758 RF C1.2020. Bul. № 2. (In Russian).

4. Evstafiev A.Yu., Kolybelsky D.S., Porfiriev Ya.V. et al. A multifunctional grease lubricant for heavy loaded friction joints. Patent 2711022 RF C1.2020. Бюл. № 2. (In Russian).

5. Kudashev S.V., Kusik Yu.S., Danilenko T.I. et al. An exfoliated polyurethane nanocomposite with polyfluoroalkyl groups Patent 2711458 RF C2.2020. Bul. № 2. (In Russian).

6. Ryshkov A.A., Ivanov D.A., Melnikov A.P. A thermostatic system to perform nanocalorimetric measurements. Patent 2711563 RF C1.2020. Bul. № 2. (In Russian).

7. Yuriev A.L., Loiko T.V., Elyash S.L., Seleznev A.A. Subnanosecond electron accelerator. Patent 2711213 RF C1.2020. Bul. № 2. (In Russian).

8. Gordienko E.V., Dosovitsky A.E., Dosovitsky G.A. et al. A method to produce fluorescent ceramics on the basis of complex oxides with garnet structure. Patent 2711318 RF C2.2020. Бюл. № 2. (In Russian).

9. Shubov L.Ya., Borisova O.N., Doronkina I.G. Wastewatertechnologies (engineering protection of hydrosphere). Scientific and technical aspects of environmental protection. 2010. № 6. P. 2-128. (In Russian).

10. Doronkina I.G., Borisova O.N. Ecological and economic efficiency of waste water treatment processes. Service in Russia and abroad. 2015. Vol. 9. № 4 (60). P. 112-121. (In Russian).

11. Shubov L.Ya., Borisova O.N., Doronkina I.G. Increase of ecoefficiency ofwaste water treatmenttechnology.Service in Russia and abroad. 2014. № 1 (48). P. 153-162. (In Russian).

12. Revin V.V., Senin P.V., Dolganov A.V. A water defluoridation method. Patent 2711741 RF C1.2020. Bul. № 3. (In Russian).

13. Meshkov I.B., Kalinina A.A., Gorodov V.V. et al. A self-hardening composition based on polydimethylsiloxane. Patent 2712558 RF C1.2020. Bul. № 4. (In Russian).

14. Borisova O.N., Shubov L.Ya. Development and research of technology of solid waste biodegradable fractionseparation. Service in Russia and abroad. 2011. № 1 (20). P. 242-251.(In Russian).

15. Shubov L.Ya., Borisova O.N. On optimization of solid wastes control in housing and public utilities. ZhKH. 2013. № 11. P. 20-29.(In Russian).

16. Grechishnik V.S., Borisova O.N. An experience of solid waste processing and the technology development tendency. In Proc. Modern problems of tourism and service. Materials of All-Russian theoretical conference of postgraduates and young scientist. 2013. P. 128-132. (In Russian).

17. Ivanov LA., Bokova E.S., Muminova S.R., Katuhin L.F. Nanotechnologies: a review of inventions and utility models. Part I. Nanotechnologies in Construction. 2020, Vol. 12, no. 1, pp. 27-34. DOI: 10.15828/2075-8545-2020-12-1-27-34.

18. Dolmatov V.Yu., Rudenko D.V., LisitsinO. N. et al. A method to obtain detonation nanodiamonds. Patent 2712551 RF C1.2020. Bul. № 4. (In Russian).

19. Ivanov LA., Borisova O.N., Muminova S.R. The inventions in nanotechnologies as practical solutions. Part I. Nanotechnologies in Construction. 2019, Vol. 11, no. 1, pp. 91-101. DOI: 10.15828/2075-8545-2019-11-1-91-101.

20. Leivi A.Ya., Yalovez A.P. A method to apply thin metal coatings. Patent 2712681 RF C1. 2020. Бюл. № 4. (In Russian).

21. Predtechensky M.R., Muradyan V.E., SIlchenko E.V. etal. A cloth with antistatical properties. Patent 2712912 RF C1.2020. Bul. № 4. (In Russian).

22. Anrau Ch.D., Rise D.L. Nanoparticles generating device. Patent 2712778 RF C2. 2020. Bul. № 4. (In Russian).

23. Ivanov LA., Razumeev K.E., Bokova E.S., Muminova S.R. The inventions in nanotechnologies aspractical solutions. Part V. Nanotechnologies in Construction. 2019, Vol. 11, no. 6, pp. 719-729. DOI: 10.15828/2075-8545-2019-11-6-719-729.

24. Skvortsova A.N., Farmakovsky B.V., Geraschenkov D.A. et al. A method to obtain functional coating on the basis of aluminium-carbon nanofibers. Patent 2709688 RF C1. 2019. Bul. № 35. (In Russian).

25. Gvozdev A.A., Komarova T.A., Baranov A.V. etal. A composition of additive for break-in oil used in gear running. Patent 2707596 RFC1. 2020. Bul. № 2. (In Russian).

26. Polyakov A.Yu., Lebedev V. A., Cieschi M.T. Eco-friendly iron-humicnanofertilizers synthesis for the prevention of iron chlorosis in soybean (glycine max) grown in calcareous soil.Frontiers in Plant Science.2019.Vol. 10. no. 413. DOI: 10.3389/ fpls.2019.00413.

27. Popkov V.I., Tolstoy P., Nevedomskiy V.N. Peroxide route to the synthesis of ultrafine $\mathrm{CeO}_{2}-\mathrm{Fe}_{2} \mathrm{O}_{3}$ nanocomposite via successive ionic layer deposition. HELIYON. 2019. Vol. 5, no. 3. DOI: 10.1016/j.heliyon.2019.e01443. 


\section{INFORMATION ABOUT THE AUTHORS}

Leonid A. Ivanov, Camd. Sci. (Eng.), Vice President of the Russian Academy of Engineering, Member of the International Journalist Federation; Gazetny per., block 9, bld. 4, Moscow, Russia, 125009, e-mail: L.a.ivanov@mail.ru

Ivan A. Kapustin, Camd. Sci. (Eng.), Assistant Professor, A.N. Kosygin Russian State University, Director General of JSC «Nauchno-proizvodstvennycentr «Electrospinning», Moskovskaya str., (dist. Zheleznodorozhny), 8-89, Balashikha, Moscow region, Russian Federation, 143987, kapustin@bk.ru

Oksana N. Borisova, Camd. Sci. (Eng.), Assistant Professor, Russian State University of Tourism and Service; Glavnaya str., 99, Cherkizovo, Moscow region, Russian Federation, 141221, borisova-on@bk.ru

Zhanna V. Pisarenko, Doctor of Economics, Assistant Professor, Saint-Petersburg State University, Economic Faculty, Department of Risk Management and Insurance, University emb., 7/9, St., Saint-Petersburg, 199034, Russian Federation, z.pisarenko@spbu.ru

Received: 31.01.2020.

Revised: 16.02.2020.

Accepted: 18.02.2020. 